\title{
Socio-Demographic Characteristics of Health Care Workers and Hepatitis B Virus (HBV) Infection in Public Teaching Hospitals in Khartoum State, Sudan
}

\author{
Taha Ahmed Elmukashfi ${ }^{1}$, Omer Ali Ibrahim ${ }^{2}$, Isam Mohamed Elkhidir ${ }^{3}$, \\ Abdelgadir Ali Bashir ${ }^{4} \&$ Mohammed Ali Awad Elkarim ${ }^{5}$ \\ ${ }^{1}$ Department of Community Medicine, Faculty of Medicine, University of Khartoum, Khartoum State, Sudan \\ ${ }^{2}$ Department of Econometrics and Social Statistics, Faculty of Economics, University of Khartoum, Khartoum \\ State, Sudan \\ ${ }^{3}$ Department of Medical Microbiology and Parasitology, Faculty of Medicine, University of Khartoum, \\ Khartoum State, Sudan \\ ${ }^{4}$ Khartoum State Ministry of Health, Khartoum State, Sudan \\ ${ }^{5}$ Department of Community Medicine, Faculty of Medicine, University of Khartoum, Khartoum State, Sudan \\ Correspondence: Taha Ahmed Elmukashfi, Department of Community Medicine, Faculty of Medicine, \\ University of Khartoum, Khartoum State, Sudan. Tel: 249-9180-96771. E-mail: tahamukashfi@hotmail.com
}

Received: April 19, 2012 Accepted: May 6, 2012 Online Published: May 21, 2012

doi:10.5539/gjhs.v4n4p37 URL: http://dx.doi.org/10.5539/gjhs.v4n4p37

\begin{abstract}
Background: HBV is second to tobacco as a known human carcinogen and the $10^{\text {th }}$ leading cause of death worldwide.

Objectives: To examine the socio-demographic characteristics of health care workers and hepatitis B virus in Public Teaching Hospitals in Khartoum State, Sudan, in 2004.

Methods: It was an observational, cross sectional, facility-based study. A total of 843 subjects were selected. It was conducted through multistage cluster sampling. The clustering was based on: type of hospital (Federal or State) and degree of exposure (type of department). For the analysis, Z-test for single proportion and some non-parametric tests such as Chi-Square test were used.

Results: Among the 843 subjects tested for HBV markers (Anti-HBc, HBsAg, HBsAb, and HBeAg), the prevalence of Anti-HBc, HBsAg, HBsAb, and $\mathrm{HBeAg}$ was found to be $57 \%, 6 \%, 37 \%$ and $9 \%$ respectively. Seroprevalence of all HBV markers was found to be statistically significant with demographic factors $(\mathrm{P}<0.05)$.

Conclusion: Infection rate, carrier rate and a profile of high infectivity rate were found to be high. The immunity rate was low. There is a significant association between HBV markers and socio-demographic characteristics. Highest rate of infection was found in State Hospitals, South and West regions, married HCWs and HCWs of age group 30-49.
\end{abstract}

Keywords: HBV markers, health care workers, public teaching hospitals, socio-demographic characteristics, Khartoum State, Sudan

\section{Introduction}

Hepatitis B virus is a widespread disease of public health importance. Nearly $5 \%$ of the world populations are currently infected with HBV (Rentería et al., 2002). Infection by HBV is the cause of up to $80 \%$ of cases of primary liver cancer, the single most important cause of cancer mortality in the world. In countries where HBV carrier rates either reach or exceed $10 \%$, hepatitis BV may account for up to $3 \%$ of total mortality ascribed to HBV infection. One third of HBV chronic carriers who survive for at least 30 years after diagnosis are expected to die due to chronic sequelae of the infection, i.e., cirrhosis and/or primary liver cancer (Rentería et al., 2002), (Lavanchy, 2004). Serologic markers for HBV were detected in $68 \%$ of sexually active heterosexuals in Port Sudan and Suakin (McCarthy et al., 1989). In Khartoum, a case - control study was done showed HBsAg positive in $67 \%$ of patients with hepatocellular carcinoma and in $4 \%$ of control (Itoshima et al., 1989). In Gezira State, 
Sudan (Khalwat \& Salem), HBsAg was $18.7 \%$ and seropositivity for any HB markers (HBsAg, Anti-HBs, or anti-HBc) was $63.9 \%$ (Hyams et al., 1989). In a cross sectional study carried in Juba, South Sudan, prevalence of HBsAg was $26 \%$ and that of Anti-HBcore was $67 \%$ (McCarthy et al., 1994).

\section{Study Area}

Khartoum State is one of the 26 states of the Sudan. Khartoum is the political capital and commercial center of the Sudan, with an area of $20140 \mathrm{Km}^{2}$, it lies between latitudes 15.10 to 16.30 degrees north and longitudes 31.35 to 34.20 degrees east. The most prominent feature is the Blue and White Niles confluence at the center of the city where the main Nile River is formed meandering up to the Mediterranean Sea. The state is divided into seven localities. Sex ratio is found to be 410 males per 1000 population (Male: female ratio is 1:1). Average size of the households is 6.1 persons per house. Children under five account for $15.1 \%$ (higher in the rural areas $14.3 \%$ ), while those under 14 years of age constitute $37.6 \%$. The working age (15-59) accounts for $57.9 \%$ of the total population (Sudan National Population Council, 1993 census).

\section{Methods}

This study was an observational, cross sectional, facility-based study. It was conducted at Public Teaching Hospitals in Khartoum State in the year 2004. A total of 843 subjects were selected, using multistage cluster sampling. The clustering was based on type of hospital (Federal or State) and degree of exposure (type of specialty). To increase the internal homogeneity of the groups, the hospitals were further divided according to whether they have all specialties, two specialties, or one specialty, to reflect the degree of exposure. Informed consent from the selected health care workers (HCWs) obtained. A pre-tested, pre-coded questionnaire was used to collect socio-demographic. $5 \mathrm{ml}$ of venous blood were collected using $10 \mathrm{ml}$ vacutainer. Sera were separated and stored at $-20^{\circ}$ centigrade, until testing. ELISA was used to screen for anti-HB core total. Reactive specimens for anti $\mathrm{HB}$ core were tested for HBs Ag. Reactive specimens for HBs Ag were tested for HBe Ag. Vaccinated HCWs and part of the reactive specimens for anti- HB core but non-reactive for HBs Ag were tested for Anti-HBs.

Data was processed using the statistical package for social sciences (SPSS), version 15. For the analysis, Z-test for single proportion and some non-parametric tests such as Chi-Square test were used, P-value of $<0.05$ was considered statistically significant.

\section{Results}

A total of 843 HCWs were interviewed and blood sample was collected; 628 (74.5\%) from Federal Teaching Hospitals, and 215 (25.5\%) from State Teaching Hospitals. The age group 30-49 years represents $58.4 \%$ of the subjects, followed by the age group less than $30(30.7 \%)$, and only $(10.9 \%)$ for more than 50 . Regarding gender representation, $366(43.4 \%)$ were males and 477 (56.6\%) were females. Four hundred and sixty $(54.6 \%) \mathrm{HCWs}$ were married. Concerning education, $269(31.9 \%) \mathrm{HCWs}$ were university graduates, 214 (25.4\%) high secondary education and five $(0.6 \%)$ Quranic education (khalwa). The health care workers were originally from the Central 288 (34.2\%), Western 235 (27.9\%), Northern 212 (25.1\%), Southern 86 (10.2\%) and Eastern Region 22 (2.6\%) of the Sudan.

The findings of the Z-test for single proportion were as follows:

4.1 Infection Rate (+ve Anti-HBc)

Four hundred and seventy seven (57\%) of the respondents had evidence of past or ongoing HBV infection. (95\% CI: $54 \%-60 \%)$.

4.2 Carrier Rate (+ve HBsAg)

Twenty seven $(6 \%)$ of the tested respondents represented the HBV carriers with a low infectivity profile. $(95 \% \mathrm{CI}$ : $5.9 \%-6.1 \%)$

4.3 Immunity Rate (+ve Anti-HBs)

Forty six (37\%) of the tested individuals were positive for Anti-HBcore. (95\% CI: 36.2\% - 37.7\%)

4.4 A Profile of High Infectivity Rate (+ve HBeAg)

Out of 27 carriers, three $(9 \%)$ were positive $(95 \%$ CI: $6.9 \%-11.1 \%)$. 
Table 1. Demographic characteristics of HCWs and the HBV markers (all values in percentages)

\begin{tabular}{|c|c|c|c|c|c|c|c|c|c|}
\hline \multirow{3}{*}{ Characteristics } & \multirow{3}{*}{$\mathbf{N}$} & \multicolumn{2}{|c|}{$\begin{array}{l}\text { Anti-HBcore } \\
(\mathrm{N}=\mathbf{8 4 3})\end{array}$} & \multicolumn{2}{|c|}{$\begin{array}{l}\text { HBsAg } \\
(\mathrm{N}=488)\end{array}$} & \multicolumn{2}{|c|}{$\begin{array}{l}\text { HBeAg } \\
(\mathrm{N}=32)\end{array}$} & \multicolumn{2}{|c|}{$\begin{array}{l}\text { Anti-HBsAg } \\
(\mathrm{N}=123)\end{array}$} \\
\hline & & $\mathbf{N}$ & $\%$ & $\mathbf{N}$ & $\%$ & $\mathbf{N}$ & $\%$ & $\mathbf{N}$ & $\%$ \\
\hline & & + & & + & & + & & + & \\
\hline Hospital & & * & & & & & & & \\
\hline Federal & 628 & 342 & 54.5 & 24 & 6.6 & 2 & 37.8 & 37 & 8.0 \\
\hline State & 215 & 135 & $62.8^{*}$ & 4 & 2.8 & 1 & 36.0 & 9 & 14.3 \\
\hline \multicolumn{10}{|l|}{ Sex } \\
\hline Male & 366 & 214 & 58.5 & 16 & 7.3 & 2 & 11.1 & 26 & 41.3 \\
\hline Female & 477 & 263 & 55.1 & 12 & 4.4 & 1 & 7.1 & 20 & 33.3 \\
\hline Age & & & & $*$ & & & & & \\
\hline$<30$ years & 259 & 131 & 50.6 & 7 & 5.2 & 2 & 22.2 & 19 & 46.3 \\
\hline $30-49$ & 492 & 292 & 59.3 & 16 & 5.4 & 1 & 5.9 & 24 & 33.8 \\
\hline $50+$ & 92 & 54 & 58.7 & 5 & 7.3 & 0 & 0.0 & 3 & 27.3 \\
\hline Residence & & $*$ & & & & & & & \\
\hline South & 86 & 58 & 67.4 & 6 & 10.2 & 0 & 0.0 & 1 & 33.3 \\
\hline North & 212 & 103 & 48.6 & 4 & 3.8 & 1 & 20 & 17 & 53.1 \\
\hline East & 22 & 12 & 54.5 & 1 & 8.3 & 0 & 0.0 & 3 & 75.0 \\
\hline West & 235 & 154 & 65.5 & 13 & 7.7 & 2 & 13.3 & 5 & 17.9 \\
\hline Center & 288 & 150 & 52.1 & 4 & 2.6 & 0 & 0 & 20 & 35.7 \\
\hline Marital Status & & $*$ & & & & & & & \\
\hline Married & 460 & 275 & 59.8 & 17 & 6.0 & 1 & 5.3 & 18 & 30.0 \\
\hline Unmarried & 381 & 202 & 53.0 & 11 & 5.3 & 2 & 15.4 & 28 & 44.4 \\
\hline Education & & $*$ & & & & & & & \\
\hline Illiterate & 97 & 36 & 37.2 & 4 & 5.5 & 0 & 0.0 & 1 & 16.7 \\
\hline Khalwa & 5 & 3 & 60.0 & 0 & 0.0 & 0 & 0.0 & 0 & 0.0 \\
\hline Primary & 59 & 30 & 55.9 & 4 & 11.8 & 0 & 0.0 & 1 & 25.0 \\
\hline Intermediate & 125 & 73 & 58.4 & 6 & 6.9 & 0 & 0.0 & 5 & 35.7 \\
\hline Secondary & 214 & 115 & 53.7 & 8 & 6.7 & 2 & 20.0 & 2 & 10.0 \\
\hline University & 269 & 140 & 52.0 & 6 & 4.2 & 1 & 14.3 & 30 & 48.4 \\
\hline Postgraduate & 74 & 42 & 56.8 & 0 & 0.0 & 0 & 0.0 & 7 & 43.8 \\
\hline \multicolumn{10}{|l|}{ Duration of work } \\
\hline$<1$ year & 73 & 35 & 47.9 & 0 & 0.0 & 0 & 0.0 & 2 & 40.0 \\
\hline 1 year. & 101 & 55 & 54.5 & 3 & 5.5 & 1 & 33.3 & 10 & 47.6 \\
\hline 5 years & 232 & 131 & 56.5 & 7 & 5.2 & 1 & 10.0 & 13 & 40.6 \\
\hline 10 years & 137 & 73 & 53.3 & 3 & 4.1 & 0 & 0.0 & 4 & 25.0 \\
\hline 15 years & 107 & 63 & 58.9 & 5 & 7.8 & 1 & 16.7 & 9 & 40.9 \\
\hline$>20$ years & 193 & 119 & 61.8 & 10 & 7.4 & 0 & 0.0 & 8 & 29.6 \\
\hline
\end{tabular}

* Result is significant at $\mathrm{P}$ value $<0.05$ according to Chi-Square test.

* For marital status two cases were missing. 


\subsection{Socio-demographic Characteristics Associated with High Prevalence of Infection (positive Anti-HBcore)}

Table 1 indicates that the highest infection rate occurred within State Teaching Hospitals with a rate of $62.8 \%$ compared with $54.5 \%$ for Federal Teaching Hospitals. With regard to the original place of residence, the Southern and the Western States obtained the highest prevalence, $67.4 \%$ and $65.5 \%$ respectively. The least prevalence (48.6\%) was found in the Northern State. Among the married HCWs 59.8\% were positive and for unmarried they were 53.0\%. For educational, the highest prevalence of Anti-HBc was associated with Quranic school (Khalwa) education $(60 \%)$, followed by intermediate $(58.4 \%)$, postgraduate $(56.8 \%)$ and illiterate $(37 \%)$.

\subsection{Socio-demographic Characteristics Associated with High Carrier Rate (HBsAg)}

The prevalence of carrier of HBV increased with increase in age: from $5.2 \%$ for the age $<30$ years to $5.4 \%$ for the age $30-49$ reaching $7.3 \%$ for the age group $50+$.

\section{Discussion}

Hepatitis BV is a blood borne virus. Infection frequently results in a chronic asymptomatic carrier state for many years before the development of symptomatic liver disease. HBV infected healthcare workers may therefore be unaware of their condition and their potential to infect patients. Healthcare workers, who perform exposure prone procedures, where injury to the worker may result in exposure of the patient's open tissues to the blood of the worker, are at increased risk of infection with blood borne viruses.

The highest infection rate was observed among the age group 30-49. This was consistent with that recorded by WHO, and with a study done in Canada (WHO, 2008), with regard to the original residency of the HCW, the South and the West Regions obtained the highest infection rate. The North Region showed the least infection rate. This is because the disease was endemic in the South and West regions and possibly other undetected factors. The obtained results were consistent with the findings recorded in Iran; in U.S.A.; and in Juba, Southern Sudan (WHO, 2008; Alavian et al., 2005; Teo \& Lok, 2006; McCarthy et al., 1994). Among the married HCWs, positive Anti-HBc was more prominent than among unmarried HCWs. Highest prevalence of Anti-HBc was associated with Quranic School (Khalwa) type of education, followed by intermediate, postgraduate and the least are the illiterate HCWs. The illiterate HCWs had least contact with patients compared to other HCWs while postgraduates were more aware of safety measures. Significant association was found between age, type of hospital, original place of residence, marital status and education of the HCW and infection rate (+ ve Anti-HBcore).

The highest carrier rate of $10.2 \%$ was found in the South, followed by $8.3 \%$ in the West and $2.6 \%$ in the Central State. Demographic characteristics, age and occupation were found to be significantly associated with carrier rate measured by HBsAg $(\mathrm{P}<0.05)$. The findings were similar to that recorded by WHO; a study done in Canada (Rentería et al., 2002; McCarthy et al., 1994), Port Sudan and Suakin, Khartoum, and Gezera, in Sudan (McCarthy et al., 1989; Itoshima et al., 1989; Hyams et al., 1989; Elshafie, 1992). The prevalence of carrier of HBV increased with increase in age: from $5.2 \%$ for the age $<30$ years to $5.4 \%$ for the age $30-49$ reaching $7.3 \%$ for the age group $50+$. The highest carrier rate occurred at the age group of 30-49. The lowest carrier rate occurred in the lowest age group i.e. $<30$ years old. Concerning the effect of place of residence on the carrier rate, the Southern and the Western Regions recorded the highest carrier rate, while the Central Region has the lowest carrier rate. This is because the disease is endemic in these areas and therefore needs further studies. However, this result was identical with that of the infection rate of HBV infection.

Out of the 27 currently infected individuals, 3 (9\%) were considered as a high profile infected people. The P-value of the Z-test for single proportion $=0.000$. The highest rate of High Profile of Infectivity occurred in the age group $30-49$. The lowest carrier rate occurred in the age group $(<30)$.

Those who were vaccinated against HBV infection or infected with HBV and developed immunity accounted for $37 \%$ (95\% CI: $34 \%-40 \%)$. The P-value of the Z-test for single proportion $=0.007$.

Completion of vaccination is recommended during training in schools of medicine, dentistry, nursing, laboratory technology, and other allied health professions, before trainees have their first contact with patient's blood and body fluids. Establishment of an occupational health unit is highly recommended in each hospital. This unit has to implement and monitor the infection control system in the hospital

\section{Conclusion}

The study showed that the infection rate among HCWs in Public Teaching Hospitals in Khartoum State measured by Anti-HBcore was found to be $57 \%$, while the carrier rate measured by HBsAg was $6 \%$ and the high profile infectivity rate measured by $\mathrm{HBeAg}$ was $9 \%$. The immunity rate measured by Anti-HBsAg was $37 \%$. Among the 
different demographic characteristics the type of hospital, original residency, marital status, and education; were statistically significant with Anti-HBcore. Increased age was found to be associated with high carrier rate.

\section{Acknowledgements}

The authors would like to express utmost gratitude to Dr. Arbab Ismail Faris and Pro. Sidieg Mohammed Ahmed of the Faculty of Economics \& Social Studies of Khartoum University who contributed a lot to the outlining the frame \& design of the sample.

Our thanks are also extended to The Government of Khartoum State for contributing to the necessary fund for this research. We are most grateful to the team of data collectors and Hamza Abdullah Mohammed Hamza of Laboratory Department of Khartoum State for their cooperation and patience.

\section{References}

Balderas-Rentería, I., Muñoz-Espinosa, L. E., Déctor-Carrillo, M. A., Martínez-Martínez, F. J., \& Barrera-Saldaña, H. A. (2002). Detection of Hepatitis B Virus in Seropositive and Seronegative patients with chronic liver disease using DNA amplification by PCR. Archives of Medical Research, 33(6), 566-571. http://dx.doi.org/10.1016/S0188-4409(02)00391-0

Elshafie, S. S. (1992). The prevalence of hepatitis B surface antigen in the Gezira (Sudan). African Journal of Medical Science, 21(1), 61-3.

Hyams, K. C., Al-Arabi, Mohamed A., Al-Tagani, Ahmed A., Messiter, James F., Al-Gaali, Abdella A., \& George, John F. (1989). Epidemiology of hepatitis B in the Gezira region of Sudan. American Journal of Tropical Medicine and Hygiene, 40(2), 200-6.

Itoshima, T., Fedail, S. S., Suliman, I., Ali, A. K., Higashi, T., \& Tsuji, T. (1989). Hepatitis B virus markers in patients with schistosomiasis, liver cirrhosis and hepatocellular carcinoma in Khartoum, Sudan. Acta Med Okayama, 43(4), 241-4.

Lavanchy, D. (2004). Hepatitis B Virus Epidemiology, Disease Burden, Treatment, and Current and Emerging Prevention and Control Measures. Journal of Viral Hepat, 11(2), 97-107. http://dx.doi.org/10.1046/j.1365-2893.2003.00487.x

McCarthy, M. C., Burans, J. P., Constantine, N. T., el-Hag, A. A., el-Tayeb, M. E., el-Dabi, M. A., ..., Hyams, K. C. (1994). Hepatitis B and C in Juba, southern Sudan: results of a serosurvey. Trans Royal Society of Tropical Medicine and Hygiene, 88(5), 534-6. http://dx.doi.org/10.1016/0035-9203(94)90150-3

McCarthy, M. C., et al. (1989). Hepatitis B and HIV in Sudan: a serosurvey for hepatitis B and human immunodeficiency virus antibodies among sexually active heterosexuals. American Journal of Tropical Medicine and Hygiene, 41(6), 726-31.

Seyed Moayed Alavian, et al. (2005). Hepatitis B prevalence and risk factors in blood donors in Ghazvin, IR.Iran. Journal of Hepatitis Monthly, 4(5), 117-122.

Sudan National Population Council, 1993 census

Teo, E. K., \& Lok, A. S. F. (2006). Epidemiology, transmission \& prevention of Hepatitis B virus infection. UpToDate: June 2006; Version 14.2.

Tepper, M. L., \& Gully, P. R. (1997). Hepatitis B. CMAJ, 156, 1033-4.

WHO. (2008). Hepatitis B Fact sheet, №204, Revised August 2008. 